\title{
About the direction of motion, polarity and multiplicity of lightning flashes hitting towers: a comparative analysis of data gathered in Brazil and Switzerland
}

\author{
O. Pinto Jr. ${ }^{1}$, D. G. Guedes ${ }^{1}$, M. M. F. Saba ${ }^{1}$, I. R. C. A. Pinto ${ }^{1}$, and M. Lacerda ${ }^{2}$ \\ ${ }^{1}$ Instituto Nacional de Pesquisas Espaciais-INPE-São José dos campos, São Paulo, Brazil \\ ${ }^{2}$ Universidade Federal do Mato Grosso, Cuibá, Mato Grosso, MT, Brazil
}

Received: 21 May 2002 - Revised: 5 November 2002 - Accepted: 8 November 2002

\begin{abstract}
After 17 years of research at Morro do Cachimbo station (MC) in Brazil, 51 flashes with strokes higher than $2 \mathrm{kA}$ were registered. The data are compared with similar data obtained from the Mount San Salvatore station (SS), Switzerland, in terms of the incidence of downward or upward flashes, polarity, and flash multiplicity. The comparison indicates that at MC the percentage of upward flashes and the multiplicity of negative downward flashes are higher than at SS, while the percentage of downward positive flashes is lower.
\end{abstract}

Key words. Meteorology and atmospheric dynamics (atmospheric electricity; lightning; instruments and techniques)

\section{Introduction}

The most comprehensive study of the current waveform characteristics of the lightning discharges was carried out for about 28 years at the Mount San Salvatore station (SS) in Switzerland (e.g. Berger, 1967; Berger et al., 1975). The study began in 1943, with a wood tower, located $914 \mathrm{~m}$ above sea level and $640 \mathrm{~m}$ above Lugano Lake. In 1958, a 60-m transmission tower (here named T1) replaced this tower. A second 60-m tower (here named T2) was erected in 1950 to obtain photographs at a distance of $365 \mathrm{~m}$ from the first tower and to increase the number of records. The altitude of its top was about $47 \mathrm{~m}$ lower than the first one. Both towers at SS used a shunt circuit for attenuation of the current that was subsequently recorded in a cathode-ray oscillograph (Berger, 1967).

In the following decades, other similar towers were erected in Italy (Garbagnati and Lo Piparo, 1970), South Africa (Eriksson, 1979), Brazil (Trignelli et al., 1995), Japan (Goto and Narita, 1994), Germany (Beierl, 1992), and Canada (Hussein et al., 1995).

In Brazil, the Morro do Cachimbo Lightning Research station (MC) was built by the Companhia Energética of Mi-

Correspondence to: O. Pinto (osmar@dge.inpe.br) nas Gerais (CEMIG) in 1985 with the goal to determine the electric parameters of direct discharges in towers. The first results obtained at MC were published by Trignelli et al. (1995). More recently, Pinto et al. (1997) presented a comparative analysis of mean peak current at MC, SS, Italy, and South Africa. Lacerda et al. (1999) presented a waveform analysis of about 22 negative downward lightning flashes obtained from 1985 to 1994 , computing the correlation between the times to peak current and to maximum derivative current, and identifying M-components in subsequent strokes. Schroeder et al. (2000) and Mello et al. (2000) presented an analysis of the peak current of first strokes covering the period from 1995 to 1998. In this work the percentage of downward and upward negative and positive flashes is computed and the multiplicity of negative downward flashes based on 51 flashes captured at MC from 1985 to 1998 (Guedes, 2001). Throughout this work we assume that a negative flash (both downward and upward) transfers negative charges to ground. A positive flash (both downward and upward), in turn, transfers positive charges to ground. Only flashes with a first stroke peak current higher than $2 \mathrm{kA}$ were considered in this study. Also, only subsequent strokes with a peak current above this threshold were considered. Flashes with a peak current lower than $2 \mathrm{kA}$ are normally considered to have only a continuing current component, following the suggestion given by Berger (1967). Statistics on these flashes are strongly dependent on the minimum current threshold of the measured instrument and were not considered in this paper. Also, no consideration was given regarding the peak current distribution, since the measurements at MC were done in the bottom of the tower, while at SS they were done in the top of the tower. Recent results have clearly shown that this difference leads to differences in the peak current measured (Guerrieri et al., 1998; Heidler et al., 2000). The results are compared with similar data (following the same $2 \mathrm{kA}$ threshold) obtained by the two towers in Switzerland from 1963 to 1974. During this period, the towers T1 and T2 captured 60 and 58 flashes, respectively. These values are of the same order of that obtained at MC. The analysis of the SS data 


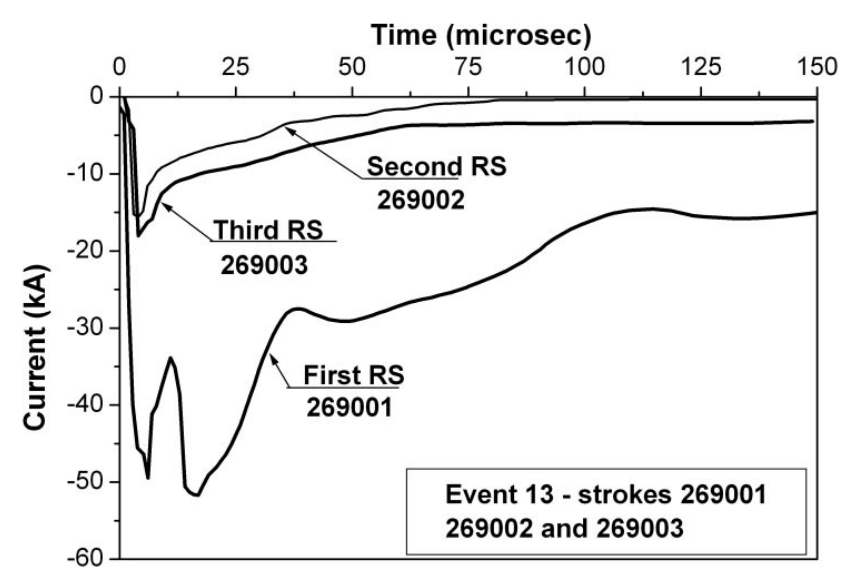

Fig. 1. The first three strokes of a negative downward 5-stroke multiple flash obtained at MC (event 13).

considering the two towers separately gives an estimation of the intrinsic variability in the data sets discussed in this work.

\section{Morro do Cachimbo station - data acquisition system}

Morro do Cachimbo station (MC) was acquired by Companhia Energética de Minas Gerais (CEMIG) from the National Electric Engineering Research Institute (NEERI), located in South Africa, and installed under the orientation of Dr. A. J. Eriksson. The station is very similar to that operated in South Africa (Eriksson, 1979). Located at $43^{\circ} 58^{\prime} \mathrm{W}$ and $20^{\circ} 00^{\prime} \mathrm{S}$, MC initiated its operations in 1985. It records the nearby cloud-to-ground lightning activity, the atmospheric electric field, and the direct current measurements. In addition, it provides photograph records and video images of the flashes striking the $60-\mathrm{m}$ metallic tower. The tower is located on the top of a mountain about $1430 \mathrm{~m}$ above sea level and $200 \mathrm{~m}$ above any other mount in the region. The current is measured by two current transducers (CT) that induce proportional voltage pulses. In a lightning event in the tower, the discharge crosses a gap before the principal CT. Current values up to $200 \mathrm{kA}$ can be measured. One shunt of $0,5 \Omega$ is prepared in a parallel path with other CT to allow the measurement of small (lower than $20 \mathrm{kA}$ ) current values with higher accuracy. The MC uses a fiber optic link, with converters $\mathrm{E} / \mathrm{O}$ and $\mathrm{O} / \mathrm{E}$, installed into an open duct with a copper plate ground system from the sensor to equipment room. The accuracy of current resolution and sampling time of the data analysed in this work was initially limited to $760 \mathrm{~A}-1 \mu \mathrm{s}$ and $116 \mathrm{~A}-0.2 \mu \mathrm{s}$ for the principal CT and the parallel CT, respectively. The sampling time of the principal CT was changed to $0.5 \mu \mathrm{s}$ in 1992 and to $0.2 \mu \mathrm{s}$ in 1993 , remaining unchanged up to the present. All events in the tower with peak current above $116 \mathrm{~A}$ are recorded. For more details, see NEERI (1985).

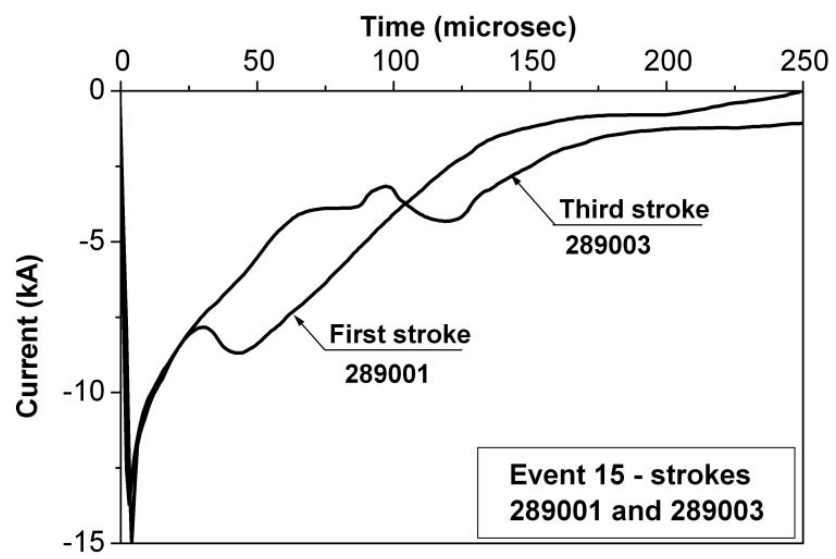

Fig. 2. Negative upward flash with 3 return strokes obtained at MC (event 15). The curve of the second stroke was not obtained.

\section{Data from Morro do Cachimbo station (MC)}

From 1985 to 1998,79 flashes with strokes larger than $2 \mathrm{kA}$ were captured, from which 51 had the current waveform recorded. The others 28 flashes had only the peak current registered (by magnetic links). We analyzed only the 51 flashes with recorded curves, from which 29 were downward flashes. Out of 29 downward flashes, 14 flashes were single flashes and 15 were multiple flashes. The total number of strokes of all multiple flashes was 89. Examples of current waveforms are presented in Figs. 1 and 2. All waveforms are presented in a scale of $150 \mu \mathrm{s}$. The lightning event is characterized by two digits and the stroke event by six digits: the first two digits represent the flash number, the third and fourth digits represent the year of occurrence, and the last two digits represent the stroke order. The direction of motion of the initial leader associated with each flash was determined by two different ways: the direction of the branches in photographic records (in about $60 \%$ of the cases), and the steepness of the stroke current curve, when no records were available or no evidence of branches are visible in the records. Figure 3 shows an example of a photographic record that indicates a downward flash. In general, the steepness of the first stroke of upward flashes is higher than the first stroke of downward flashes, and similar to that of subsequent strokes of downward flashes. Figure 4 illustrates the criterion adopted in this paper. First, the tangent to the front shape is calculated, considering it as the line joining the $30 \%$ and 90\% amplitude intercepts. Then, the time when this line intercepts the time axis is determined. Finally, the time interval between this time and the time correspondent to the peak current is determined. If the current curve presents two peaks (a common feature), the time corresponds to the peak with higher amplitude. If this time interval is less than $10 \mu \mathrm{s}$, the flash was considered as an upward flash. In most cases, upward flashes identified by photographic records present time intervals shorter than $7 \mu$ s. The criterion was applied to the flashes where the direction of motion was identified by photographic records. A very good agreement was obtained. The 


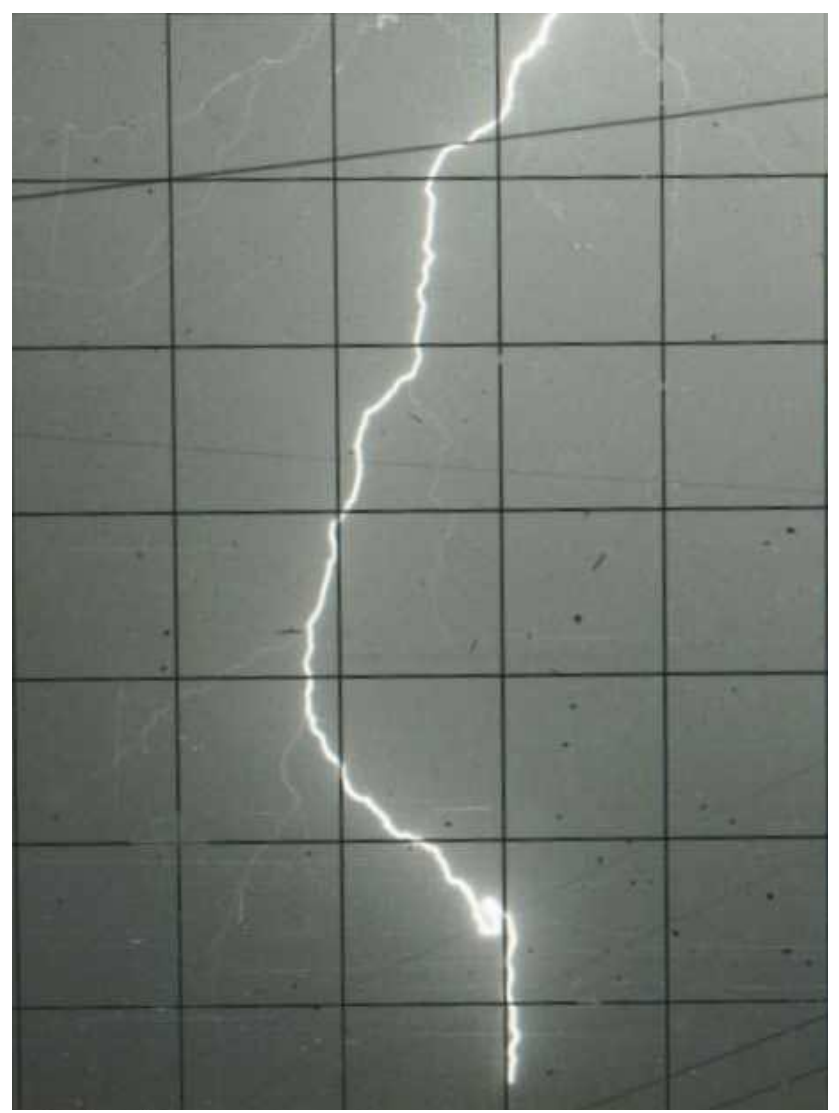

Fig. 3. Example of a photographic record of a downward flash observed at MC.

polarity of the strokes was determined by the direction of the current, and the multiplicity of the negative downward flashes was determined by the number of pulses in the current waveform above $2 \mathrm{kA}$. Most strokes of the downward flashes had an intensity above $5 \mathrm{kA}$.

\section{Data from Mount San Salvatore station (SS)}

We have accessed and analysed 118 current curves recorded during the period from 1963 to 1974 at Mount San Salvatore. The station is located at approximately $45^{\circ} 59^{\prime} \mathrm{N}$ of latitude. The flashes were captured by two identical towers ( $\mathrm{T} 1$ and T2). The tower T1 captured 60 flashes, from which 42 were downward ( 29 singles and 13 multiples - the total number of strokes of all multiple flashes was 96). The tower T2 captured 58 flashes, from which 49 were downward (32 singles and 17 multiples - the total number of strokes of all multiple flashes was 105). Figures 5 and 6 show some examples of current waveforms recorded at SS. In these figures, the lightning event is characterized by two digits and the stroke event by five digits and one letter: the first two digits represent the year, the third to fifth digits represent the flash number, and the letter $(a, b, e t c$.$) represent the stroke order. The same cri-$ teria described in item 3 were used to analyze the SS data. In particular, the same criterion illustrated in Fig. 4 was used to

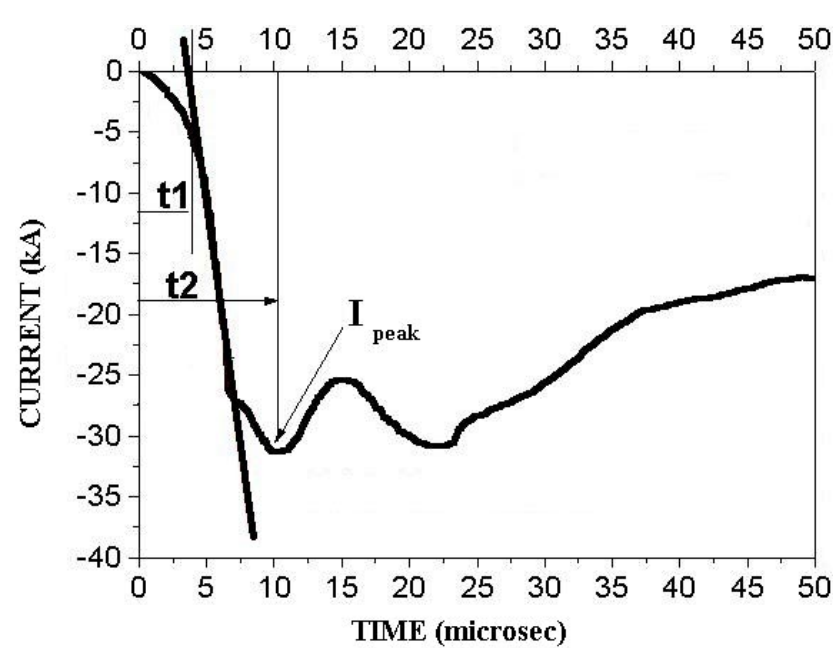

Fig. 4. Criterion adopted to determine the flash direction. It was applied for the cases that no photographic records were available or no evidence of branches are visible in the records (see text for details).

determine the directions in the SS for the cases in which no photographic determination was available. Also, we applied the criteria for the other cases in the SS (with photographic determination made by Berger) and found a very good agreement.

\section{Results}

The main results are presented in Table 1. From this table, it can be seen that the results obtained from the towers $\mathrm{T} 1$ and $\mathrm{T} 2$ in Switzerland are similar, while the MC results show significant differences from the SS results. The main differences are:

1. The percentage of upward flashes with strokes more intense than $2 \mathrm{kA}$ at $\mathrm{MC}(41.2 \%)$ is much higher than those at SS towers (20\% for T1 and $6.8 \%$ for $\mathrm{T} 2$ ), in spite of the same height of the towers. This difference may be related to different atmospheric and/or ground conditions in the tower locations. The atmospheric conditions include near-surface parameters, like wind and humidity, and storm parameters, like charge structure and cloud base height. The ground conditions include tower parameters, like its height, grounding system and shape, and topographic parameters, like the altitude of the base of the tower with respect to sea level and with respect to the nearby terrain. Except for the storm parameters, the combination of the other factors determines the degree to which the electrostatic field in the vicinity of the top of the tower is intensified by the presence of a charged leader. The intensification of the electric field is believed to be responsible for the occurrence of an upward flash. The storm parameters, in turn, define the rate and the intensity of intracloud flashes in the location of the towers. A comparative analysis of 
Table 1. Lightning data at SS (T1 and T2) and MC

\begin{tabular}{|c|c|c|c|c|c|c|c|c|}
\hline \multicolumn{2}{|c|}{ Tower } & \multirow[t]{3}{*}{ Total } & \multicolumn{4}{|c|}{ Negatives } & \multicolumn{2}{|c|}{ Positives } \\
\hline & & & \multirow[t]{2}{*}{ Upward } & \multicolumn{3}{|c|}{ Downward } & \multirow[t]{2}{*}{ Upward } & \multirow[t]{2}{*}{ Downward } \\
\hline & & & & Total & Single & Multiple & & \\
\hline \multirow{2}{*}{ SS } & $\mathrm{T} 1$ & 60 & $6(10 \%)$ & $42(70 \%)$ & $29(69 \%)$ & $13(31 \%)$ & $6(10 \%)$ & $6(10 \%)$ \\
\hline & $\mathrm{T} 2$ & 58 & $2(3.4 \%)$ & $49(84.5 \%)$ & $32(65.3 \%)$ & $17(34.7 \%)$ & $2(3.4 \%)$ & $5(8.7 \%)$ \\
\hline \multicolumn{2}{|c|}{$\mathrm{MC}$} & 51 & $10(19.6 \%)$ & $29(56.9 \%)$ & $14(48.3 \%)$ & $15(51.7 \%)$ & $11(21.6 \%)$ & $1(1.9 \%)$ \\
\hline
\end{tabular}

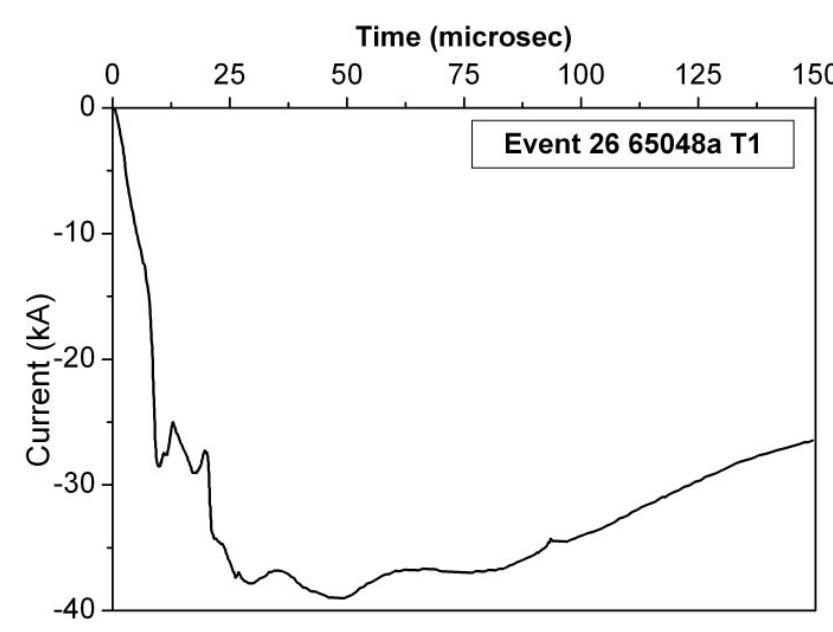

Fig. 5. Negative downward single flash recorded at SS - tower T1 (event 26).

the altitude of the top of the towers with respect to the sea level $(914 \mathrm{~m}$ for T1, $867 \mathrm{~m}$ for T2, and $1430 \mathrm{~m}$ for $\mathrm{MC})$ and with respect to the nearby terrain $(640 \mathrm{~m}$ for $\mathrm{T} 1,593 \mathrm{~m}$ for $\mathrm{T} 2$, and $200 \mathrm{~m}$ for MC) indicates that apparently the altitude of the tower with respect to the sea level is more important than that with respect to the nearby terrain. However, this assumption depends on the influence of the other factors, which, due to the lack of data, is not well known. Some authors (e.g. Orville and Berger, 1973), however, have suggested that the electric field irradiated by intracloud flashes may be responsible for the beginning of upward flashes from the towers. Based on this suggestion, a different electrical structure of the thunderstorms in the location of the towers would explain the difference observed in the percentage of upward flashes. For instance, assuming that intracloud flashes in the location of the MC are more frequent and intense than in the location of the SS, a reasonable (although but not proved) assumption considering the latitudes of the stations, the occurrence of upward flashes at MC would probably be higher than at SS. In summary, no conclusive explanation for the observed difference in the percentage of upward flashes can be obtained due to the lack of complete information about all the conditions in the location of the towers.

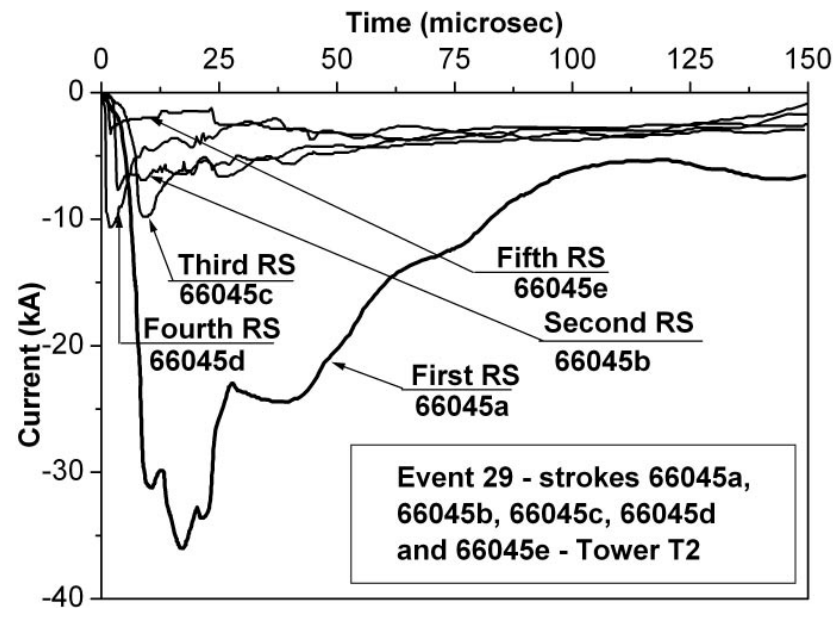

Fig. 6. Negative downward 6-stroke multiple flash recorded at SS tower T2 (event 29).

2. The percentage of multiple negative downward flashes at $\mathrm{MC}(51.7 \%)$ is higher than those at SS $(31 \%$ for T1 and $34.7 \%$ for T2). Figure 7 shows the distribution of the number of strokes per flash in downward negative flashes at MC and SS (for towers T1 and T2). The highest number of strokes per flash (14) was recorded at MC. Two hypotheses may be invoked to explain this difference: different latitudes or different predominant meteorological systems. Recent results obtained in the United States by Orville and Huffines (2001) have indicated that the multiplicity of negative flashes has regional variations. The authors speculate that these variations may be related to variations in the horizontal dimensions of the thunderstorms at different locations. Such a hypothesis, if proved, could explain the observed difference found in this work.

3. The percentage of positive downward flashes at MC $(1.9 \%)$ is lower than those at SS (10\% for T1 and $8.7 \%$ for T2). The same two hypotheses cited in the item 2 might be invoked to explain this difference: different latitudes or different predominant meteorological systems. Recent results obtained in the United States by Orville and Huffines (2001) have indicated that the percentage of positive flashes depends more on the differences in the thunderstorm morphology and evolution 


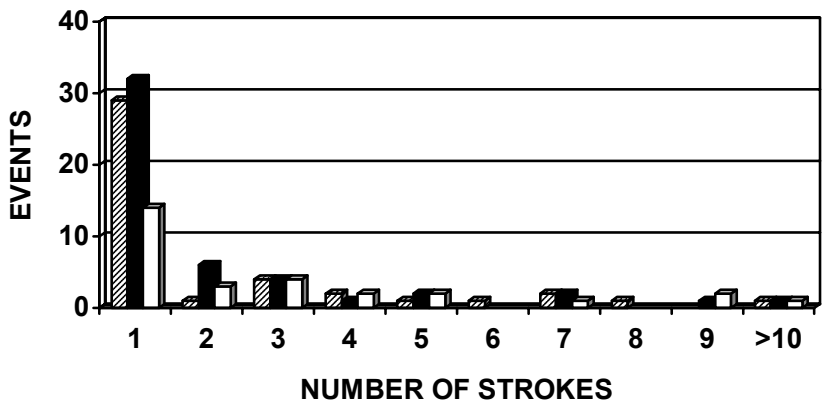

Fig. 7. Distribution of the number of strokes per flash in negative downward flashes at MC and SS (for towers T1 and T2).

than on the latitude. In consequence, the observed difference in the percentage of positive flashes probably reflects a difference in the predominant thunderstorm characteristics in the tower locations.

\section{Conclusions}

In this work we presented an analysis of 51 flashes captured from 1985 to 1998 at the Morro do Cachimbo station (MC), located in the state of Minas Gerais, Brazil. Adopting some criteria, we calculated the percentage of downward and upward flashes of negative and positive polarities. Also, we calculated the percentage of single and multiple negative downward flashes. We compared the results with similar ones obtained for two towers at Mount San Salvatore station (SS) in Switzerland from 1964 to 1975 , using the same criteria. The main differences were: the percentage of upward flashes was higher at MC than at SS; the percentage of multiple negative downward flashes was higher at MC than at SS; and the percentage of positive downward flashes was lower at MC than at SS. Some hypotheses to explain the observed differences were presented. However, further work is necessary to completely understand the reasons for these differences. In particular, we suggest that the same criteria described in this work should be applied to other towers around the world.

Acknowledgements. The authors would like to thanks Dr. Richard Orville for kindly providing the original data from Mont San Salvatore Station, the Companhia Energética de Minas Gerais (CEMIG) for providing the data from Morro do Cachimbo Station, and the Conselho Nacional de Pesquisas e Desenvolvimento (CNPq) and the Fundação de Àmparo a Pesquisa do Estado de São Paulo (FAPESP) for supporting through the research.

Topical Editor J.-P. Duvel thanks S. Chauzy and another referee for their help in evaluating this paper.

\section{References}

Beierl. O.: Front shape parameters of negative subsequent strokes measured at the Peissenberg tower, Proceedings of the 21st International Conference on Lightning Protection, Berlin, September, 1992.
Berger, K.: Novel Observations on Lightning Discharges: Results of Research on Mount San Salvatore, Journal of the Franklin Institute, 283(6), 478-525, 1967.

Berger, K., Anderson, R. B., and Kroninger, H.: Parameters of Lightning Flashes. Electra - Study Committee no. 33 - Cigré 41, 3-37, 1975.

Eriksson, A. J.: The lightning ground flash - an engineering study, Thesis (Ph. D. in Philosophy in the Faculty of Engineering - University of Natal), Pretoria, South Africa, 400 p., December, 1979.

Garbagnati, E. and Lo Piparo, G. B.: Stazionale sperimentale per il relievo delle caratteristiche dei fulmini, L'Elettrotecnica, 57 (7), 288-297, 1970.

Goto, Y. and Narita, K. I.: Electrical characteristics of winter lightning, J. Atmos. Terr. Phys., 57(5), 449-458, 1994.

Guedes, D. G.: Análise de Curvas de Corrente de Relâmpagos em torres, MSc. Thesis, Instituto Nacional de Pesquisas Espaciais (INPE), February, 2001.

Guerrieri, S., Nucci, C. A. A., Rachidi, F., and Rubinstein, M.: On the influence of elevated strike objects directly measured and indirectly estimated lightning currents, IEEE Transactions on Power Delivery, 13(4), 1543-1555, 1998.

Heidler, F., Zischank, W., and Wiesinger, J.: Statistics of lightning current parameters and related nearby magnetic fields measured at the Peissenberg tower. Proceedings of the 25th International Conference on Lightning Protection, Rhodes, Greece, 18-22 September 2000.

Hussein, A., Janischewskyj, M., Chang, J.-S., Shostak, V., Chisolm, W. A. A., Dzurevych, P., and Kawasaki, Z.-I.: Simultaneous measurement of lightning parameters for strokes to the Toronto CN Tower, J. Geophys. Res., 100, 8853-8861, 1995.

Lacerda, M., Pinto, Jr., O., Pinto, I. R. C. A., Diniz, J. H., and Carvalho, A. M.: Analysis of Negative Downward Lightning Current Curves from 1985 to 1994 at Morro do Cachimbo Research station (Brazil), Proceedings of 11th International Conference on Atmospheric Electricity, Alabama, June, 1999.

Mello, J. C. D., Schroeder, M. A., and Visacro Filho, S.: Enhancement of Morro do Cachimbo Station facilities for measurements of lightning currents, Proceedings of the Ground 2000 International Conference on Grounding and Earthling, pp. 11-14, June $18-21,2000$

NEERI: (National Electrical Engineering Research Institute), CEMIG Lightning research station system operation manual: Electric Power, Pretoria, South Africa, 1985.

Orville, R. E. and Berger, K.: An unusual lightning flash initiated by an upward-propagating leader, J. Geophys. Res., 78, 21, 4520 4525, 1973.

Orville, R. E. and Huffines, G. R.: Cloud-to-ground lightning in the USA: NLDN results in the first decade, 1989-98, Mon. Wea Rev., 129, 1179-1193, 2001.

Pinto, Jr., O., Pinto, I. R. C. A., Lacerda, M., Carvalho, A. M., Diniz, J. H., and Cherchiglia, L. C. L.: Are equatorial negative lightning flashes more intense than those at higher latitudes? J. Atmos. Solar Terr. Phys., 59 (15), 1881-1883, 1997.

Schroeder, M. A. O., Soares, Jr., A., Visacro Filho, S., Cherchiglia, L. C. L., Souza, V. J., Diniz, J. H., and Carvalho, A. M.: Evaluation of directly measured lightning parameters. Proceedings of the 5th International Symposium on Lightning Protection, May, 2000.

Triginelli, W. A. C., Carvalho, A. M., Diniz, J. H., and Cherchiglia, L. C. L.: Principais parÂmetros aplicÁveis a estudos de engenharia, Proceedings of the III International Symposium on Lightning Protection, SÃo Paulo, 1995. 